Victor Aguiar, Adriane Santos, João Sobral, Marli Everling *

\title{
A abordagem de design e materiais no âmbito do PPGDesign/ Univille
}

Victor R. L. Aguiar

Dr.; Univ. da Região de Joinville <contato@ograndevendedor.com>

Adriane S. Santos

Dra.; Univ. da Região de Joinville <drishibata@gmail.com>

João E. C. Sobral

Dr.; Univ. da Região de Joinville <sobral41@gmail.com>

Marli T. Everling

Dra.; Univ. da Região de Joinville <marli.everling@gmail.com>
Resumo Este relato apresenta a estruturação dos conteúdos técnico-científicos associados à disciplina de Materiais e Processos de Fabricação no âmbito do Programa de Pós-Graduação em Design da Universidade da Região de Joinville (PPGDesign/Univille). Em virtude da natureza profissional do mestrado, a translação de conhecimentos de base científica e tecnológica em capacitação técnica, considerando a sua aplicabilidade, foi o norte da disciplina.

Palavras chave Design, materiais, processos.

\section{An Approach Relied on Design and Materials in Univille's PPGDesign Realm}

Abstract This report presents the structuring of technical-scientific contents associated with the subject Materials and Processes within the Graduate Program in Design of the University of the Region of Joinville (PPGDesign /Univille). Due to the professional nature of the master's degree, the translation of scientific and technological knowledge into technical qualification, including applicability, was the north of the discipline.

Keywords Design, materials, processes. 


\section{Relato dos Objetivos da Disciplina: Do evento de materiais à apresentação do seminário}

A Disciplina de Materiais e Processos de Fabricação se constitui em uma das disciplinas eletivas do Programa de Pós-Graduação em Design da Universidade da Região de Joinville. Em virtude da natureza profissional do mestrado, a disciplina integra o conjunto de conteúdos de cunho mais tecnológico, orientados para a profissionalização e para conexões com o setor industrial e produtivo, considerando o escopo 'materiais e processos de fabricação'. A área de concentração (Sustentabilidade) do Programa, suas linhas de pesquisa e atuação técnico-científica (Processo de Produção e Design e Produção Tecnológica e Sustentabilidade), bem como a ementa da disciplina estão descritas na figura 1 .

Figura 1: Área de concentração, linhas de pesquisa e atuação do PPGDesign Univille e ementa da disciplina

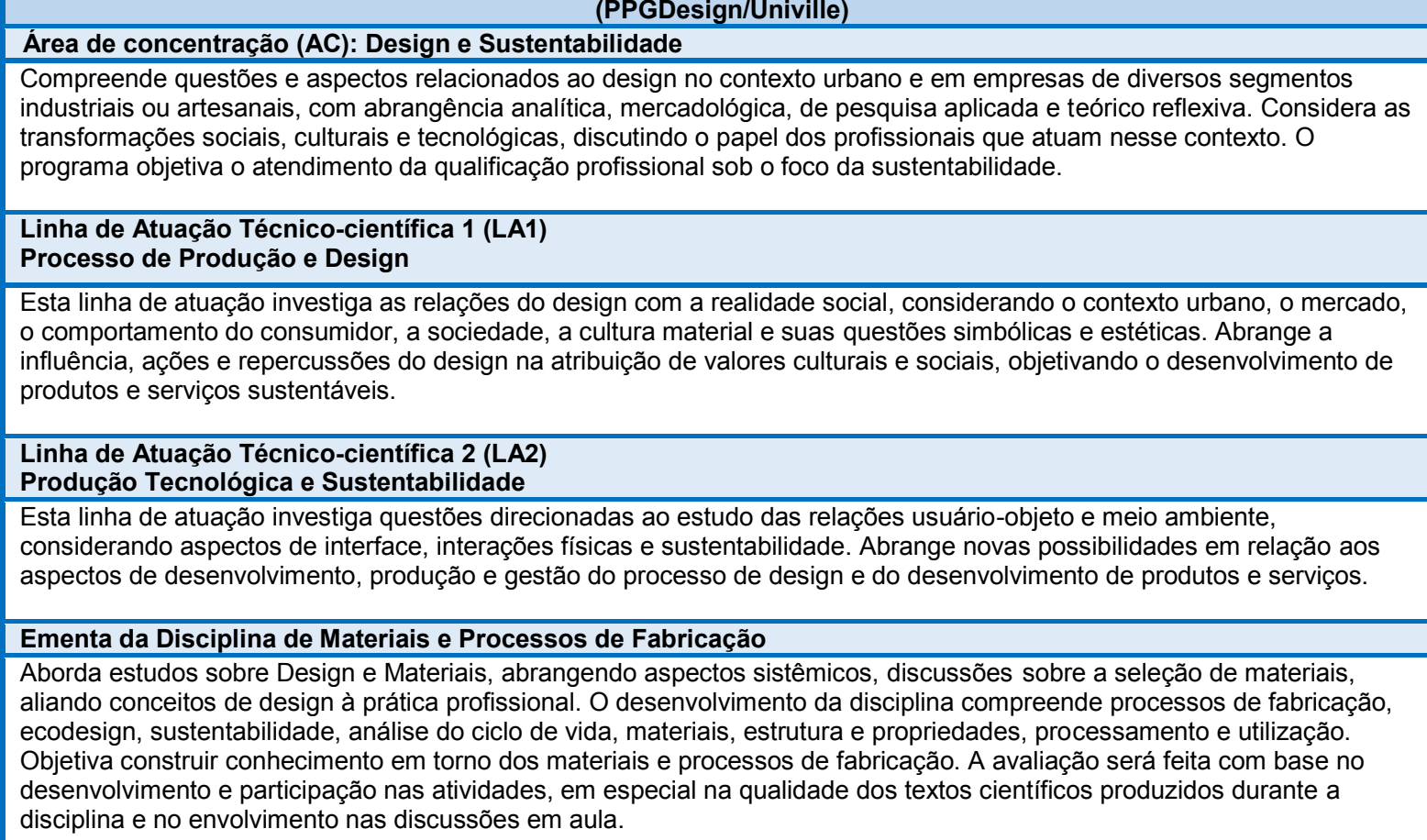

Em 2017 o PPGDesign, em conjunto com a graduação em Design da Univille, sediaram o II Congresso Internacional e VIII Workshop: Design \& Materiais 2017. O evento ocorreu no período entre 11 e 14 de junho e a disciplina foi programada para iniciar na mesma semana, para que o evento se constituísse em marco imersivo em discussões associadas a design e materiais. A partir desta premissa, a disciplina foi estruturada em quatro partes: (1) conexão com os conteúdos abordados no evento; (2) palestras e visitas técnicas; (3) atividades de laboratório; (4) seminário apresentado pelos alunos. Este relato visa apresentar as abordagens conduzidas em cada etapa (conforme ilustração da figura 2). 
Figura 2: Estrutura da disciplina

\begin{tabular}{|c|c|c|}
\hline DATAS & ATIVIDADES & OBSERVAÇÕES \\
\hline $\begin{array}{l}13 / 06 \\
14 / 06\end{array}$ & $\begin{array}{l}\text { Design\&Materiais } \\
\text { Design\&Materiais }\end{array}$ & $\begin{array}{l}\text { O evento associado à disciplina } \\
\text { O evento associado à disciplina }\end{array}$ \\
\hline $20 / 06$ & $\begin{array}{l}\text { Palestra Engenharia de Materiais } \\
\text { seguida de visita a FGM }\end{array}$ & Local de encontro: Sala do INOVAPARQ no PERINI \\
\hline $21 / 06$ & Atividade de integração interdisciplinar & Atividade interdisciplinar com 'Design e Relações de Uso' \\
\hline $27 / 06$ & Visita EMBRACO FUNDIÇÃO & Local de encontro: EMBRACO FUNDIÇÃO (Pirabeiraba) - \\
\hline $28 / 06$ & $\begin{array}{l}\text { A joia - simbolismo e história } \\
\text { Conhecendo o Laboratório de Joias } \\
\text { Técnicas construtivas }\end{array}$ & Aula na sala e no Laboratório de Joias \\
\hline $04 / 07$ & $\begin{array}{l}\text { Técnicas de fundição e confecção de } \\
\text { joias (proposta de projeto) }\end{array}$ & \\
\hline 05/07 & Visita Fastparts ou execução do projeto & Vai depender do andamento do projeto \\
\hline $25 / 07$ & Execução do projeto & Aula no Laboratório de Joias \\
\hline 26/07 & Execução do projeto & Aula no Laboratório de Joias \\
\hline $01 / 08$ & $\begin{array}{l}\text { Seminário: Processos de fabricação e } \\
\text { materiais }\end{array}$ & $\begin{array}{l}\text { Com a participação do Prof. Sacchelli e Eng. Willian } \\
\text { Em } 8 \text { grupos, realizar seminário a partir da obra "Como se faz: } \\
82 \text { técnicas de fabricação para design de produtos " de Chris }\end{array}$ \\
\hline 02/08 & $\begin{array}{l}\text { Seminário: Processos de fabricação e } \\
\text { materias }\end{array}$ & Lefteri \\
\hline 08/08 & Apresentação dos projetos de Joias & Com a participação dos Profs. Victor e Shibata \\
\hline
\end{tabular}

\section{Conteúdos abordados no evento de Design e Materiais}

Em sua segunda edição, o evento objetivou ser uma importante referência na área, visando promover a compreensão da associação entre conhecimentos da área de design, materiais e processos no desenvolvimento da competitividade nacional. $O$ evento foi estruturado em torno do tema "Novas Experiências: dos materiais naturais aos materiais para a indústria 4". Os eixos temáticos que direcionaram a disseminação de conhecimento relacionado à pesquisa e ao desenvolvimento no âmbito dos projetos, materiais e processos, foram: (ET1) Materiais Tradicionais: projetos, materiais e processos com a aplicação dos conceitos, técnicas e tecnologias tradicionais, considerando a manualidade, como nos âmbitos artesanal, industrial, de patrimônio, restauro, estruturas, superfícies, revestimento, acabamentos, meios gráficos, têxteis, entre outros. (ET2) Materiais Inovadores: projetos, materiais e processos com a aplicação dos conceitos, técnicas e tecnologias inovadoras, nos contextos disruptivo ou incremental, como nos âmbitos das estruturas, superfícies, revestimentos e acabamentos contemporâneos e/ou inteligentes, entre outros. (ET3) Materiais Sustentáveis: projetos, materiais e processos com a aplicação dos conceitos, técnicas e tecnologias sustentáveis, como nos âmbitos das abordagens tradicionais, inovadoras, experimentais, entre outras. (ET4) Materiais Experimentais: projetos, materiais e processos com a aplicação de técnicas e tecnologias em fase experimental, como nos âmbitos das abordagens tradicionais, inovadoras, sustentáveis, entre outras (figura 3). 
Figura 3: Tema e eixos temáticos do evento disponibilizados no site do evento.

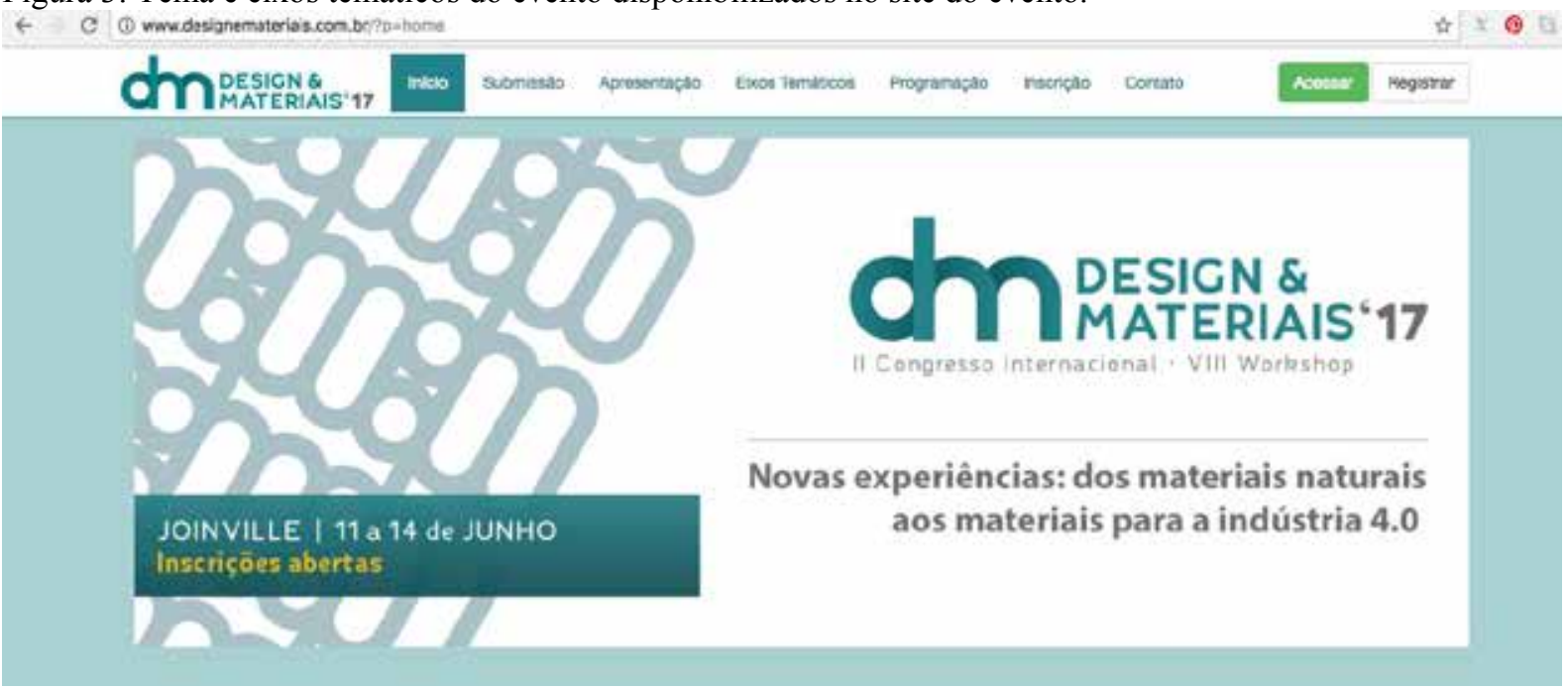

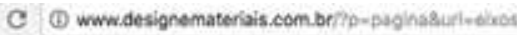

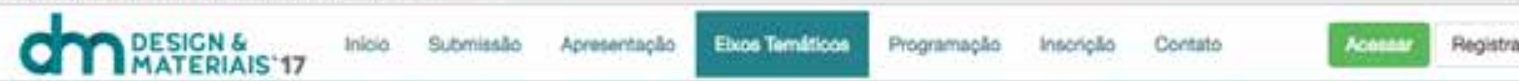

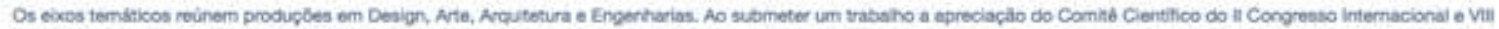

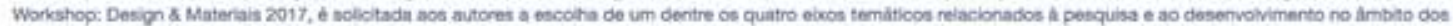
projetos, materiais e procespos, contorme segue:

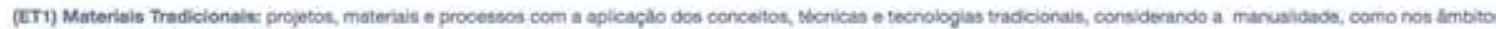

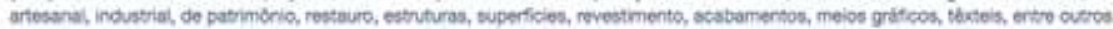

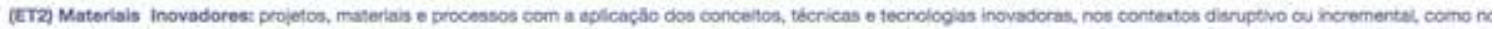

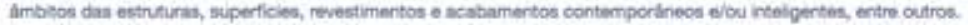

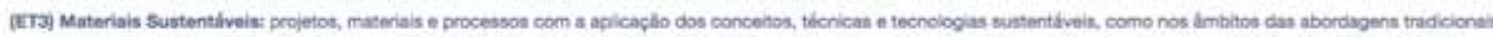
inovadoras, experimentals, entele outras.

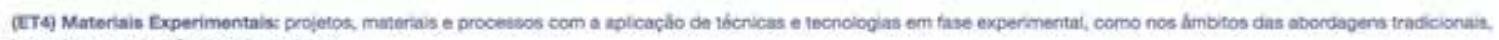
inovadorns, suatertives, entre outras.

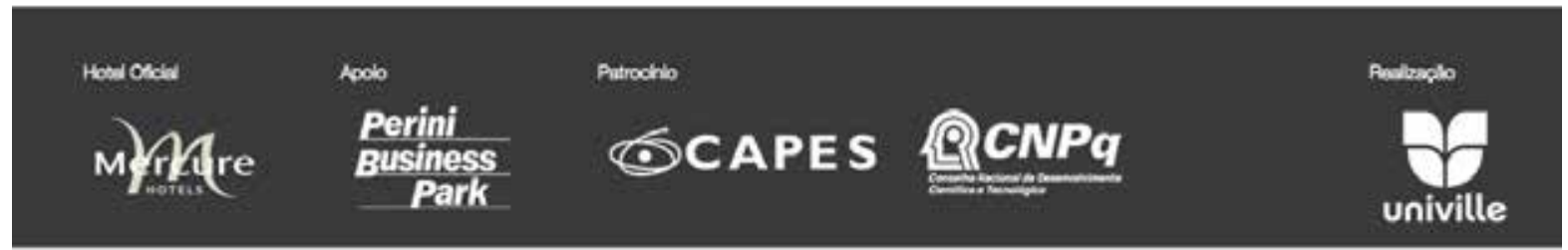

A programação do evento iniciou no dia 11, com a recepção dos participantes, e ao longo de três dias contou com seis palestras nacionais e duas palestras internacionais; ocorreram três mesas redondas e sessões técnicas orais e de pôsteres, exposição de protótipos e workshops, conforme quadro 1. 
Quadro 1: Programação do evento.

\begin{tabular}{|c|c|c|}
\hline 12 de junho & 13 de junho & 14 de junho \\
\hline Abertura do evento & $\begin{array}{l}\text { Palestra Nacional } \\
\text { Uso de resíduos e cargas minerais } \\
\text { na otimização de propriedades } \\
\text { térmicas e de restauro de } \\
\text { materiais cimentícios } \\
\text { Antonio Eduardo Martinelli }\end{array}$ & $\begin{array}{l}\text { Palestra internacional } \\
\text { Dialetos da matéria e teatralidade } \\
\text { nos produtos partilhados" } \\
\text { Paulo Bago D'uva (Universidade } \\
\text { do Aveiro/Lisboa) }\end{array}$ \\
\hline Café & Café & Café \\
\hline $\begin{array}{l}\text { Palestra internacional } \\
\text { Innovative material solutions } \\
\text { empowering industry } 4.0 \\
\text { Micol Costi } \\
\text { Material ConneXion Italia } \\
\text { Mesa-Redonda } \\
\text { Materiais e inovação }\end{array}$ & $\begin{array}{l}\text { Palestra nacional } \\
\text { O papel do Designer na Economia } \\
\text { Circular e Consumo Consciente: } \\
\text { Caminhos para criar, produzir e } \\
\text { consumir com Responsabilidade } \\
\text { Bruno Temer/Matéria brasil } \\
\text { Palestra nacional } \\
\text { Civilização do Bambu - Design e } \\
\text { Sustentabilidade } \\
\text { Lúcio Ventania } \\
\text { (Cerbambu) }\end{array}$ & $\begin{array}{l}\text { Palestra nacional } \\
\text { Relações multidimensionais do } \\
\text { design emocional com as texturas } \\
\text { e os materiais } \\
\text { Everton Amaral da Silva/UFRGS } \\
\text { Palestra nacional } \\
\text { Resíduos: a matéria-prima da } \\
\text { indústria do futuro } \\
\text { Fabiano André Trein (RS) }\end{array}$ \\
\hline Almoço & Almoço & Almoço \\
\hline $\begin{array}{l}\text { Encontro de coordenadores } \\
\text { de curso de Pós graduação em } \\
\text { Design }\end{array}$ & $\begin{array}{l}\text { Palestra nacional } \\
\text { Investigação no campo do Design } \\
\text { e materiais: cenário brasileiro } \\
\text { Sebastiana Lana }\end{array}$ & $\begin{array}{l}\text { Mesa-Redonda } \\
\text { Materiais experimentais e } \\
\text { inovadores }\end{array}$ \\
\hline Sessões técnicas orais & Mesa-Redonda & Visita técnica \\
\hline $\begin{array}{l}\text { Workshops } \\
\text { Sessões técnicas orais }\end{array}$ & $\begin{array}{l}\text { Materiais tradicionais e } \\
\text { sustentáveis }\end{array}$ & \\
\hline Sessões técnicas - Postêr & Sessões técnicas orais & \\
\hline Exposição - Protótipos & & \\
\hline
\end{tabular}

A temática transcendeu o evento e foi explorada como conteúdo nas duas primeiras aulas da disciplina (impactando em sua continuidade).

\section{Visitas Técnicas}

As visitas técnicas ocorreram nos dias 20 e 27 de julho, e 05 de agosto (conforme figura 4) e incluíram, respectivamente, empresas como Biocicle, FGM e Embraco. Os temas explorados nas visitas foram engenharia de materiais, processos e acompanhamento de projetos. 
Figura 4: Planejamento das atividades

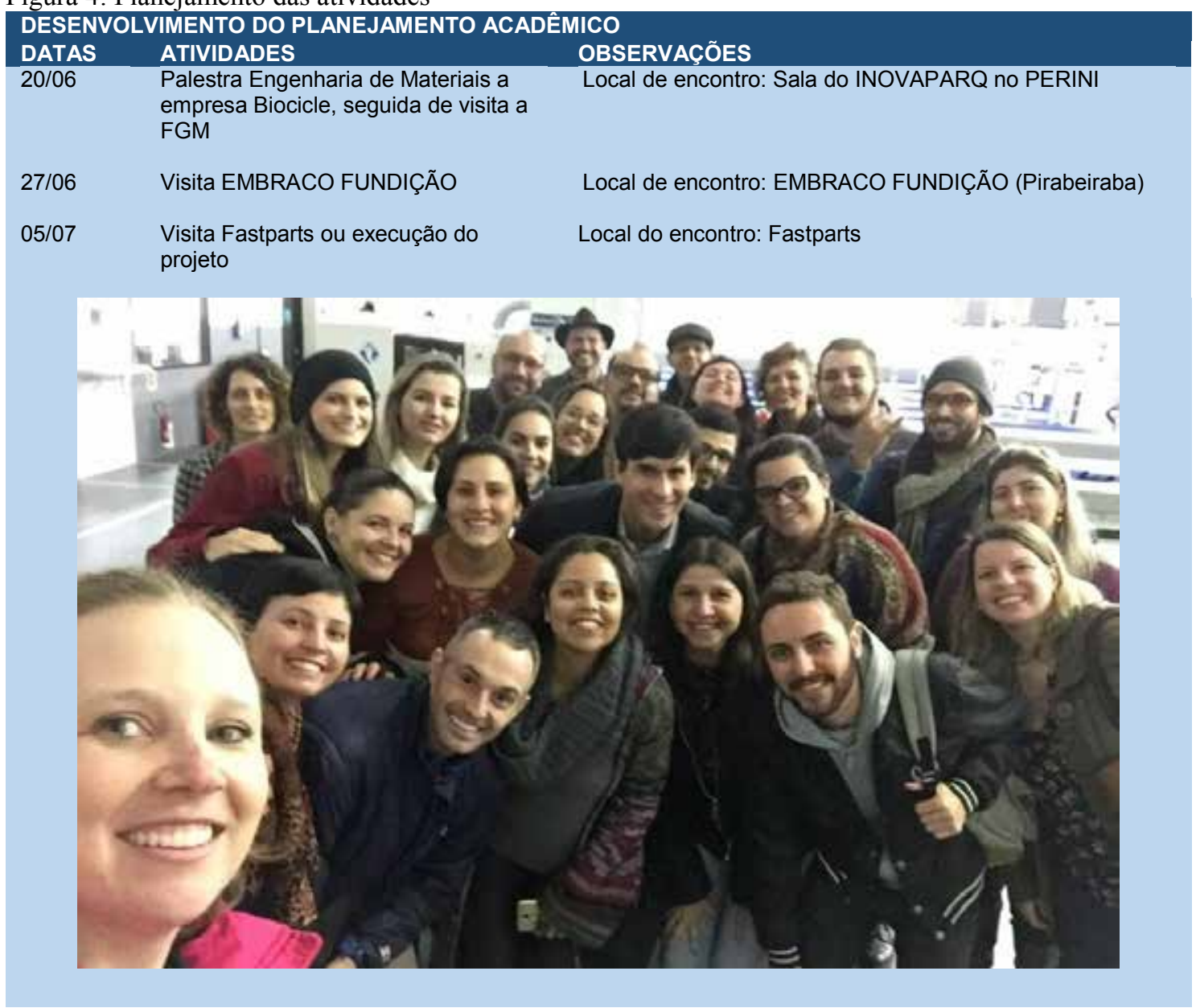

A figura destaca a programação das visitas e palestras e apresenta os discentes em atividades na Biocicle, na qual ocorreu a palestra com o Engenheiro e Mestre da área de Materiais William Wiggers.

Faz-se necessário salientar que visitas técnicas, uma forma de aproximação com o mundo empresarial e a pesquisa aplicada, são uma das premissas do Mestrado Profissional.

\section{Atividades de Laboratório}

As aulas de laboratório ocorreram nos dias 28 de julho, 04, 25, 26 de julho e culminaram com a apresentação dos projetos no dia 08 de agosto (conforme figura 5). A intenção das atividades de laboratório foi a experimentação de primeira mão com materiais e processo associados ao pensamento projetual. 
Figura 5: Planejamento das atividades de laboratório

DESENVOLVIMENTO DO PLANEJAMENTO ACADÉMICO

$\begin{array}{lll}\text { DATAS } & \text { ATIVIDADES } & \text { OBSERVAÇÕES } \\ 28 / 06 & \text { A joia - simbolismo e história } & \text { Aula na sala e no Laboratório de Joias } \\ & \text { Conhecendo o Laboratório de Joias } & \\ & \text { Técnis } & \end{array}$

Técnicas construtivas

04/07 Técnicas de fundição e confecção de joias (proposta de projeto)

25/07 Execução do projeto

Aula no Laboratório de Joias

26/07 Execução do projeto

08/08 Apresentação dos projetos de Jóias

Aula no Laboratório de Joias

Com a participação dos Profs. Victor e Shibata

As imagens apresentadas na figura 6 evidenciam o fazer e a experimentação conduzidos na disciplina.

Figura 6: Atividades práticas conduzidas no laboratório de joias.

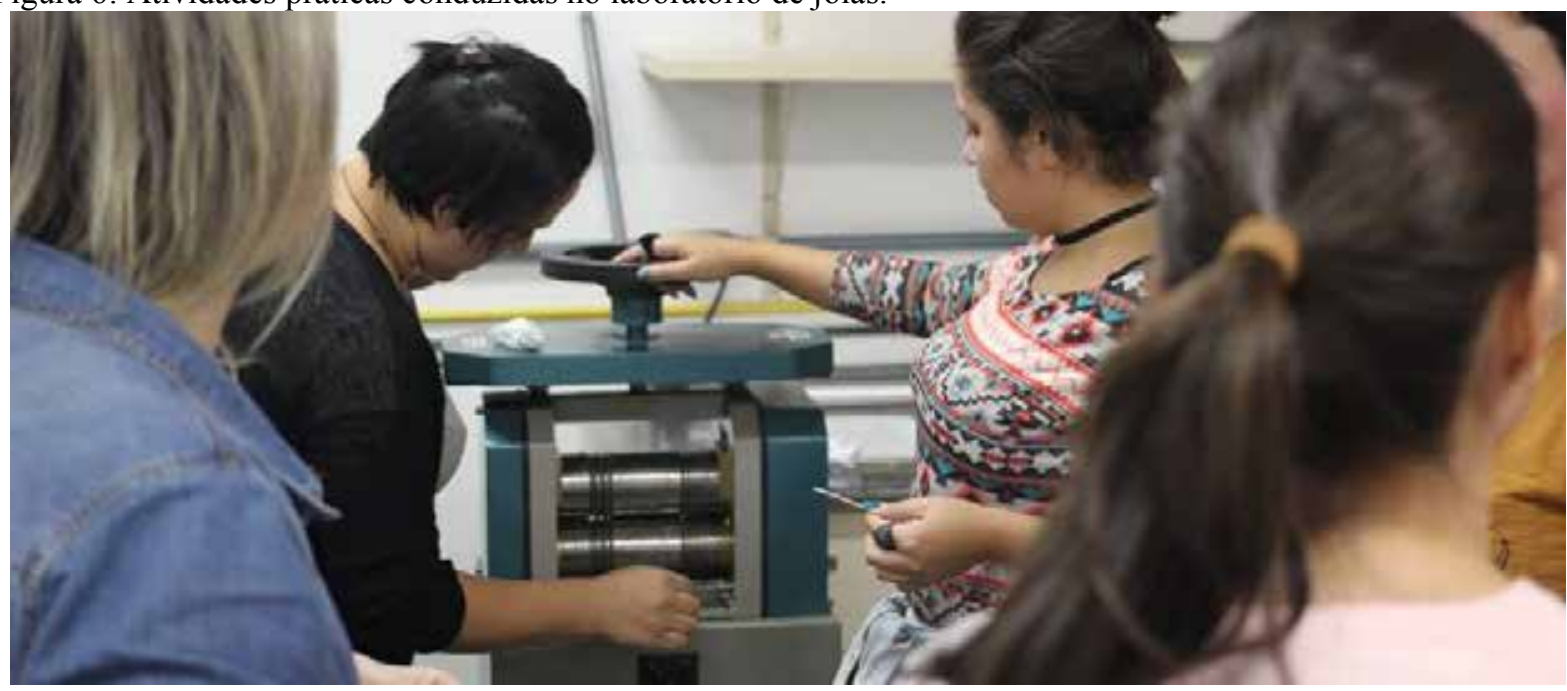



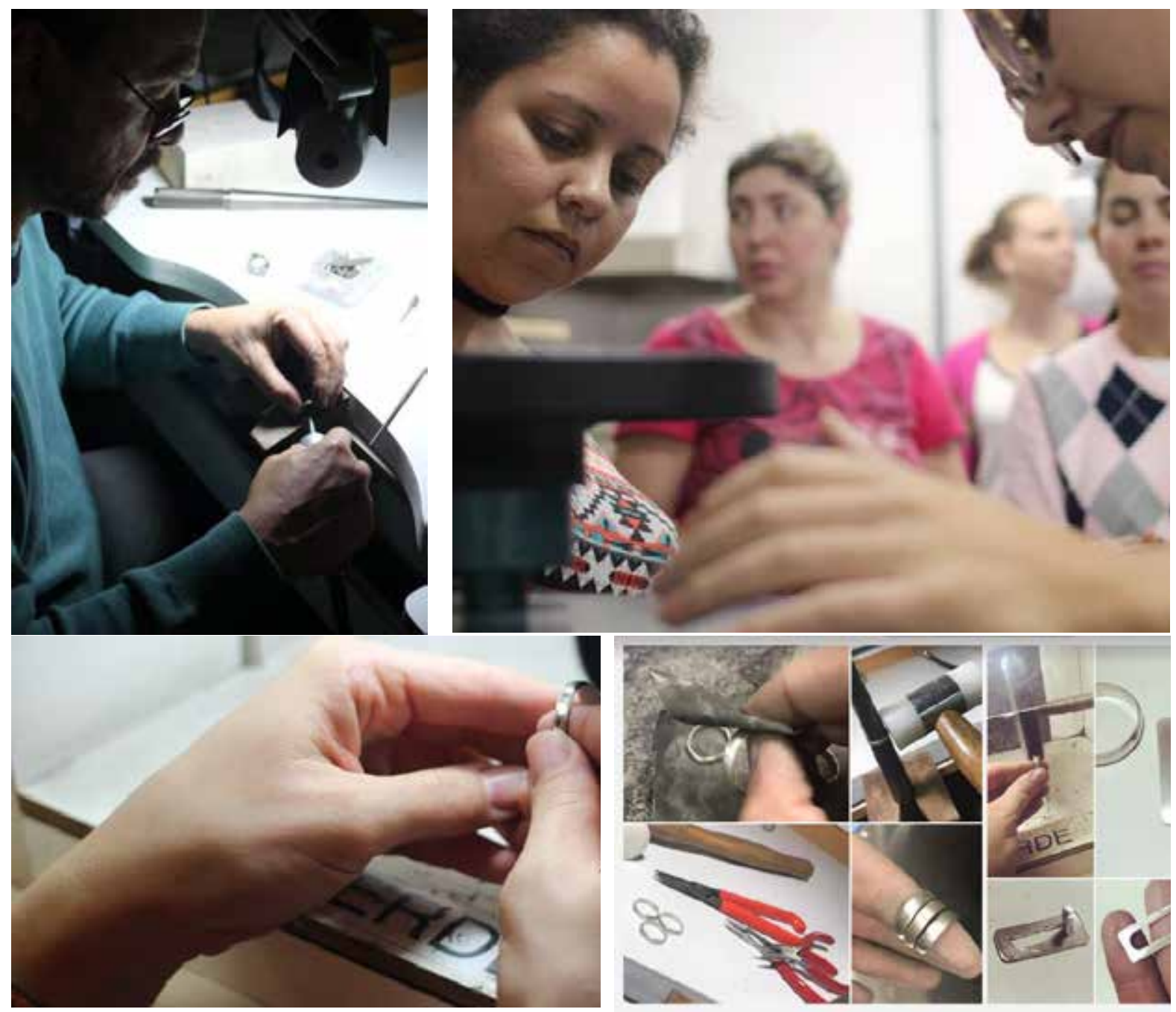

As imagens apresentadas na figura 7 representam alguns dos resultados obtidos nas atividades de laboratório.

Figura 7: Propostas desenvolvidas ao longo das atividades.

formas geometricas | fosco x britho | preenchido $\mathrm{x}$ vazado
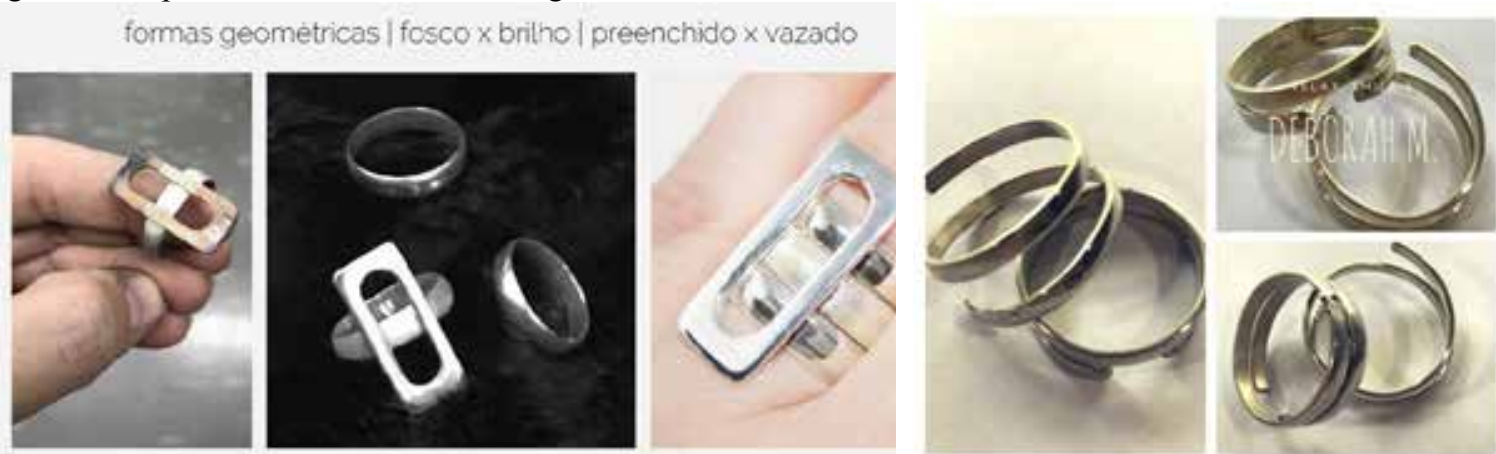

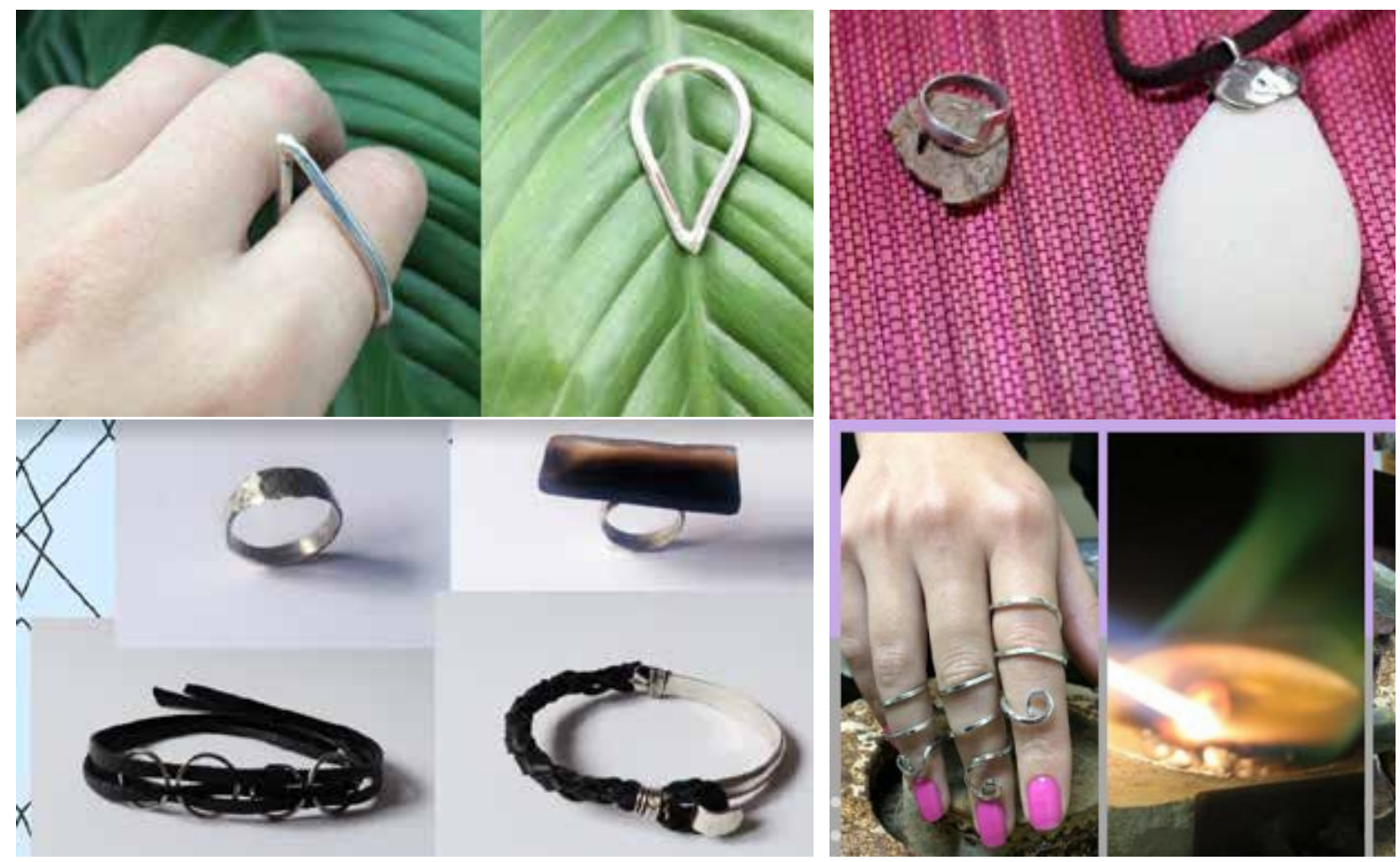

Por meio de relatos informais, os alunos manifestaram sua satisfação em poderem desenvolver uma atividade eminentemente prática, do tipo "hands on", possibilitando para a grande maioria a descoberta de novas habilidades e de novos campos de interesse.

\section{Seminário final da Disciplina}

O seminário ocorreu nos dias 01 e 02 de agosto, a partir da obra obra "Como se faz: 82 técnicas de fabricação para design de produtos", de Chris Lefteri. Os estudantes foram divididos em 8 grupos e, tendo como base um capítulo da obra, foram instigados a investigarem os processos produtivos e materiais envolvidos nos mesmos.

Figura 8: Planejamento das atividades de seminário

$\begin{array}{lll}\text { DESENVOLVIMENTO DO PLANEJAMENTO ACADÊMICO } \\ \text { DATAS } & \text { ATIVIDADES } & \text { OBSERVAÇõES } \\ 01 / 08 & \text { Seminário: Processos de fabricação e } & \text { Com a participação do Prof. Sacchelli e Eng. Willian } \\ & \text { materiais } & \text { Em } 8 \text { grupos, realizar seminário a partir da obra "Como se faz: } \\ & \begin{array}{l}\text { Seminário: Processos de fabricação e } \\ \text { materias }\end{array} & \begin{array}{l}\text { Lefteri } \\ \text { masicas de fabricação para design de produtos " de Chris }\end{array} \\ & \end{array}$

Considerando que poucos alunos possuem formação técnica, apropriar-se de conceitos como usinagem, dobra e repuxo, corte e furação, polimerização, dentre outros, foi um grande desafio. Tendo em vista esta realidade, procurou-se por meio da presença de dois engenheiros (um mecânico e outro de materiais) oferecer um suporte técnico, complementando as apresentações e evitando que algum conceito pudesse ser erroneamente abordado.

Ao final, os convidados comentaram sobre sua surpresa quanto ao nível dos seminários e ao aprendizado dos alunos, considerando, como já citado, o não domínio prévio quanto às temáticas. 


\section{Considerações Finais}

Um Mestrado Profissional diferencia-se de um programa acadêmico pelo seu foco na pesquisa aplicada e na sua aproximação com o ambiente organizacional. Do ponto de vista dos alunos, este direcionamento se materializa em sua realidade profissional, ou seja, a maior parte está atuando em organizações, concomitantemente aos seus estudos no mestrado.

Tendo em vista esta realidade, ao planejar-se uma disciplina, o corpo docente procura encontrar o melhor equilíbrio entre os estudos teóricos e a prática, a aplicação dos conteúdos e, inclusive, a relevância para os discentes. Com a disciplina de Materiais e Processos de Fabricação, conforme relatado neste artigo, não poderia ser diferente.

Percebe-se claramente esta preocupação técnico-científica no momento em que a disciplina se inicia durante um dos maiores congressos sobre materiais (o evento Design e Materiais), passando por visitas técnicas guiadas, o desenvolvimento de um artefato (uma joia) e a apresentação de seminários sobre técnicas de produção e materiais.

Ao final da disciplina, o corpo docente sentiu-se satisfeito por ter "entregue um produto" adequado com a filosofia do Mestrado Profissional, mas a maior realização é decorrente dos relatos dos alunos e pela demonstração de sua satisfação em ter cursado esta disciplina. Somese ainda o depoimento de dois especialistas na área (engenheiros convidados para os seminários), atestando o nível de envolvimento, pesquisa e de apropriação de conteúdos dos estudantes.

\section{Referências}

LEFTERI, Chris. Como se faz: 82 técnicas de fabricação para design de produtos. São Paulo, SP: Editora Blucher, 2009.

\section{Agradecimentos}

Carolina Hadlich, Daiane Laís Fontana, Daniel Giovane Galdino, Deborah Cristine Mahfud, Fernanda Soares Rios, Franciele Vaz, Jonas Daniel Pôrto, Mara Rubia Theis, Mayra Camargo, Michelle Françoise Haswany de Almeida, Soleni dos Santos Kuhn Sette, Anelise Bittencourt Gerceski, Bernardo Linhares Marchesini, Carla Feder Wick, Cristiane Machado Hoffmeister, Débora Cristina Almeida, Fernanda da Silva Adiers, Giorgio Leandro de Souza, João Antonio de Menezes Neto, Joseana Maria Ribeiro, Leonardo Calixto Colin Cecyn, Rafaela Rodrigues, Ricardo Dalbosco, Scheila Raldi, Silvana Silva Reiter Witkoski, William Amphilóquio [discentes da disciplina]. 